\title{
ORIXÁ OU DIABO: A CONSTRUÇÃO IMAGÉTICA DE EXU NO BRASIL
}

\author{
Rychelmy Imbiriba Veiga ${ }^{1}$
}

DOI 10.26512/revistacalundu.v4i2.35815

Fiz meu ensino fundamental em uma escola evangélica e ali compreendi que a religião que eu praticava não era igual a de meus colegas da Escola Batista que frequentava, pois eles seguiam os fundamentos de um livro "sagrado", a Bíblia. Era ao redor deste livro que nos reuníamos nas aulas de religião e nas celebrações das diversas datas comemorativas. Os professores usavam todas suas capacidades pedagógicas para explaná-lo. Foi com essa sede de descobrimento do mundo, em um sistema letrado, que me vi ávido por livros que falassem sobre o candomblé.

Assim, no começo de minha adolescência, na casa de uma mãe de santo de Xangô, descubro um volume de um livro de Pierre Verger: Orixás: deuses iorubás na África e no Novo Mundo (1981). Aquele livro me foi mostrado como algo importante, que continha segredos, e me foi permitido folheá-lo enquanto meus pais realizavam as cerimonias rotineiras do terreiro. Além de um texto muito atrativo, o que me chamou muito a atenção foram as inúmeras fotos que esse autor fizera tanto na África quanto no Brasil, mostrando as semelhanças ritualisticas entre esses dois territórios.

Foi a primeira vez que pensei em nossa religião para fora do terreiro, atravessando fronteiras e tradições longínquas. Para os adeptos do candomblé, um trabalho como o de Verger nas mãos de um número cada vez maior de adeptos escolarizados acabou por transformar a realidade dos cultos afro-brasileiros, criando no imaginário das religiões de matriz africana no Brasil, a busca pela África. A Antropologia, neste sentido, foi decisiva na configuração do candomblé atual e os trabalhos nascentes das experiências dos antropólogos em torno das casas eleitas como tradicionais, contribuíram para a primazia das casas de nação Nagô.

\footnotetext{
${ }^{1}$ Mestre em Estudos Étnicos e Africanos/CEAO/UFBA. E- mail: rychelmy@ hotmail.com.
} 
A partir de 1930, a antropologia reconhece o candomblé como um campo possível de pesquisa. Estudiosos brasileiros e estrangeiros como Nina Rodrigues, Arthur Ramos, Edison Carneiro, Ruth Landes, Donald Pierson, entre outros, fazem o resgate histórico e antropológico dessa religiosidade. Outras gerações de pesquisadores, que tiveram como base estes, acima citados, tanto no sentido de continuar suas investigações quanto de questionar certos paradigmas em que se basearam, resgatam valores africanos desse orixá, rompendo com uma visão estigmatizada do candomblé e, especialmente, de Exu. (VEIGA, 2018, p. 22)

Essa antropologia (hoje adjetivada como antropologia afro-brasileira) continuou crescendo nas gerações seguintes de pesquisadores, dentre os quais podemos citar uma nova geração de clássicos, tais como:

Pierre Verger, Vivaldo da Costa Lima, Juana Elbein dos Santos e Deoscoredes Maximiliano dos Santos, o Mestre Didi, entre outros que, inclusive, parte de uma relação como candomblé diferente dos anteriores, alguns com um pertencimento intenso. Com base nessas pesquisas que eram consumidas pelo de santo, em espacial, os integrantes do movimento negro, principalmente na década de 1970, Exu deixa de ser o diabo e resgata aspectos originais da tradição africana (VEIGA, 2018, p. 23).

No campo das visualidades, temos a antropologia visual, que utiliza da imagem (fotografia ou vídeos) de forma não apenas auxiliar, mas como forma de engendrar discurso como um documento. Entretanto, em especial sobre a fotografia - que representa uma imagem congelada é pertinente considerar que:

O significado de uma fotografia está sempre inevitavelmente sujeito a uma moldura cultural, envolto num discurso fotográfico, que limita as suas possíveis funções, os seus significados e mesmo as nossas expectativas e leituras em relação a esta, e como tal deve ser encarado criticamente (CALDEIRA, 2017, p. 176).

Essa capacidade de ter um olhar crítico sobre as fotografias é o objetivo deste ensaio. Alheio à grande contribuição de Verger para a legitimação e reconhecimento do Candomblé - sendo ele também religioso, uma vez que a comparação entre os cultos dos dois lados do oceano mostravam semelhanças irrefutáveis - as imagens, em especial as fotos de Verger, serviram para legitimar as religiões afro-brasileiras.

As imagens desempenham um papel crucial na criação da experiência com o sagrado, expressando e formando as diferentes visões do sobrenatural, assumidas em diferentes culturas e épocas. As histórias das imagens no candomblé também 
apresentam seus percalços, como a perseguição sofrida pelas casas de culto pela polícia, que constituiu como crime a prática ritual, logo, a relação imagética deveria ser evitada, para não virar prova irrefutável de contravenção penal. A proibição que se deu para que as pessoas não fossem fotografadas nas casas de culto, ou mesmo em estados de transe, foi então atribuída a uma suposta aversão das divindades; porém, desde a década de 1940, os registros de pessoas e de cerimonias feitos nas fotos de Verger, por exemplo, vêm desencadeando questões e debates em torno do tema. A antropologia, de alguma forma, conseguiu fazer registros que se tornaram históricos.

Para nosso melhor diálogo, analisarei como a imagem do orixá Exu, que carregou o estigma da demonização como herança do sincretismo religioso, vem sendo transformada no decorrer dos últimos anos. Exu é o Orixá mais humano entre todos, nem completamente bom, nem completamente mau.

Desde o contato da cultura europeia com o continente africano, o choque cultural esteve presente e o imaginário eurocêntrico atribuiu ao orixá uma carga negativa, seja devido ao seu caráter humano, à sua sexualidade aguçada, ou à forma antropomórfica, principalmente fálica, de seus objetos de culto, levando vários missionários a criarem a partir deste orixá o diabo cristão. Logo, no processo de cristianização, Exu torna-se a fonte de todos os males, a personificação do mau. A identificação desse orixá com o diabo se consolidou nos dicionários e nos escritos de diversos estudiosos desde o começo da colonização até os dias atuais, como em Crowther (1852), Maupoil (1938) e Abraham (1958); e foi essa mentalidade propagada pelo colonizador que encontrou eco no Brasil colonial.

Na construção do candomblé, na busca pela legitimidade de um culto aceitável pela sociedade, o culto a Exu deveria ser escondido aos olhos dos não iniciados. Isso influenciou o modo como o xirê, a roda constitutiva das cerimonias públicas, foi instituído. Exu deveria ser agradado a portas fechadas antes das festividades públicas, para não aparecer ao público em geral e para não atrapalhar a festa. A fim de fazer a comunicação entre os humanos e as divindades, mediador entre estes dois mundos, foi impossível anular o culto ao Orixá, mas seu ritual se tornou interno e secreto. Até hoje, nas casas tradicionais da Bahia, as cantigas aos orixás no xirê começam pela saudação a Ogum.

Na liturgia iorubá, para além das ideias colonialistas, Exu é um orixá muito complexo. Ligado ao começo da vida na terra, ele é o equivalente ao Adão cristão, a massa primordial que ganha vida com o sopro divino de Olodumare, tendo nessa forma 
primordial a forma de Yangi, a pedra vermelha de laterita, a lama em estado bruto, destino reconstituinte de todos os seres humanos após sua vida na terra. Ele está ligado à multiplicidade, ao crescimento, e é o mensageiro, responsável pelo movimento e pelas sensações do corpo, como frio, o calor e a fome - sensações relacionadas com o bará, o Exu do corpo constituinte de todos os seres vivos.

Exu é o responsável pela sexualidade humana e é representado sempre pela forma fálica, como podemos ver nesta descrição do século XIX:

O culto do falo é exibido com despudor. Vê-se por toda a parte o horrível instrumento que Liber inventou para servir às abomináveis manobras de sua paixão: nas casas, nas ruas, nas praças públicas. É encontrado isolado; os falóforos, às vezes, carregam-no com grande pompa; em certas procissões, agitam-no com ostentação e apontamno para as jovens, no meio das danças e dos risos de uma população sem pudor. Os negros são bem inspirados quando fazem desse instrumento o atributo a Elegbara, personificação do demônio (BOUCHE, 1885, p. 121).

Embora a figura fálica seja um dos mais importantes atributos em seus objetos de culto, esta nem sempre está representada de forma óbvia, sendo comum que o orixá seja representado por um chapéu que cai por suas costas, numa cauda fálica, ou por vezes em esculturas com penteados fálicos. A sexualidade pode ser também representada pelo prazer oral, em várias esculturas, como no ato de chupar o próprio dedo, assobiar ou tocar flauta. À Exu são atribuídos ainda os sonhos eróticos, o adultério e toda relação sexual ilícita. Para entender esse processo, devemos levar em consideração também os valores sociais vigentes nas sociedades africanas, a relação com o corpo e a necessidade da fertilização, de ter famílias grandes, para o sucesso social e financeiro das mesmas.

Exu, no Brasil, mantém alguns de seus atributos, porém, com a socialização dos negros africanos e a construção de novas formas de culto, como a umbanda e a quimbanda - religiosidades construídas no sincretismo - as associações ao diabo cristão começam a moldar o imaginário popular de maneira diferente da Africana. Dessa associação, nasce a representatividade do tridente, arma de Netuno na mitologia romana, ou seu equivalente Poseidon na mitologia grega, bem como de demônios inferiores que passam a fazer parte do imaginário religioso coletivo. A imagem da mulher, em sua associação com Exu, associa-se à figura da Pombagira, considerada uma mulher lasciva, promíscua e de caráter ambíguo. Essa associação ao diabo se torna 
evidente também nas diversas imagens vendidas pelas lojas especializadas em cultos afro-brasileiros, quando é representado por uma tez de cor vermelha e com chifres. No Brasil, principalmente na umbanda, Exu está associado a espíritos "menos evoluídos":

Os exus são, pois, os escravos que não aceitam seu destino, que se revoltam contra os senhores, que os matam com o veneno e a feitiçaria. Nos cosmos umbandistas, são depreciados, situados fora do mundo dos espíritos evoluídos, nas trevas da ignorância, mas, ao mesmo tempo, valorizados em razão do poder que essa posição marginal lhes dá. São poderosos por serem impuros (CAPONE, 2009, p. 102).

O sincretismo acabou promovendo uma modalidade de culto misto, em casas de candomblé que cultuam tanto a divindade Exu, quanto casas que adotam o culto a essas entidades, denominadas "catiços" ou "escravos". Nessas casas, é comum assentar um casal de entidades, o Exu e a Pombagira.

Devido ao forte sincretismo, as iniciações a esse orixá no Brasil tornaram-se motivo de contradições, e, embora nosso interesse nesta pesquisa seja entender a influência das imagens de Exu captadas pela ótica de Verger, é impossível não se deter sobre os estereótipos atrelados a esta divindade. As casas de culto mais ortodoxas da tradição iorubá no Brasil, ditas Ketu, pelo menos aquelas consideradas casas matrizes, oficialmente não iniciam pessoas para Exu. Não se nega que existam filhos deste orixá, porém quando isso acontece, se inicia a pessoa pra Ogum, seu irmão mítico e orixá muito próximo. Muitas vezes essa prática gera discussões acirradas, como mostra Verger:

\begin{abstract}
Uma delas [das filhas de Exu] faleceu recentemente na Bahia. Foi iniciada por volta de 1936 e, com o sincretismo de Exu com o Diabo não deixa de dar-lhe um aspecto desagradável; murmurava-se que haviam pregado uma peça nela. Foi assentado Esú e não Ogum, o verdadeiro senhor de sua cabeça, ou, mais exatamente, um Esú servidor de Ogum, que o acompanhava, é quem teria sido assentado, fazendo-se as obrigações para Esú com as folhas que lhe são consagradas. Isso teve como consequência o afastamento de Ogum, que desde essa época queixava-se de ter sido negligenciado e acabou matando aquela a quem reivindicava para ele (VERGER, 1999, p. 132).
\end{abstract}

O processo de africanização do candomblé (VALLADO, 1999; MELLO, 2008) transformou também a relação das casas de santo com o orixá Exu. Embora as casas 
matrizes não o iniciem, é cada vez mais comum que as casas que descendem delas o façam. Nos últimos anos, podemos ver casas tradicionais iniciando homens pra Exu, como o Pilão de Prata, o Terreiro do Cobre e o Opô Aganju.

Nas casas onde se inicia Exu, existe o cuidado de delimitar quais as fronteiras entre o que é cristalizado na africanidade e os modelos de culto organizados a princípio no Brasil. Até mesmo em casas matrizes é usual, por exemplo, o uso de assentamentos rituais com tridentes, atribuição, como já foi colocado, do culto a Exu no novo mundo. É sempre um dilema em muitas casas a feitura ou não deste orixá, pois, por um lado, se busca a legitimação de uma raiz nobre, quanto mais esteja ligada a uma casa matriz, pela fidelidade à sua tradição — portanto, quanto mais "pura", mais difícil se torna realizar a iniciação. Por outro lado, uma pessoa que se propõe a cultuar este orixá demonstra ser um sacerdote ou uma sacerdotisa com um conhecimento do culto muito grande, uma vez que é capaz de manipular o axé de um orixá tão poderoso e raro.

Os escritos e registros imagéticos de Verger sobre Exu (1999), tanto na África quanto no Brasil, buscam legitimar as imagens do culto africano. Em nenhum momento, em suas obras, ele fala sobre como o orixá é representado usualmente, tampouco fotografa imagens ou assentamentos ao modo brasileiro tão comum em casas tradicionais, até mesmo nas casas onde realizou suas pesquisas e era ligado às liturgias. Ele deu ênfase a poucos assentamentos que mantinham uma ligação mais estreita, porém menos comum, com a África. No capítulo em que o autor fala sobre Exu no Brasil, há certa contradição, pois, segundo os informantes aos quais ele recorre para a pesquisa, existiriam 21 qualidades de Exu, as quais descreve com nomes africanos, como Alaketu, Lonan, Jelu, Jigidi, dentre outros. Nos dois parágrafos seguintes, ele descreve a casa de uma iniciada para Exu, onde encontra diversos assentamentos do orixá. Porém, com nomes característicos da umbanda, como: Sete Facadas, Mulambinho, Vira, dentre outros, e, de certa forma, faz vista grossa para esses deslizes etnográficos.

É interessante que em um retrato feito por Verger na década de 1940 há um registro da incorporação de uma Iaô de Exu, de um modo que não seria provável, devido ao entendimento que se tinha deste orixá na época. O capacete pontiagudo, que no mito africano esconde uma faca na cabeça de Exu, os símbolos fálicos em sua cintura, as cabaças, as fileiras de búzios e o colar de chifre de boi, bem como o ogó, bastão em forma de falo, são elementos do culto iorubá resgatados nos últimos anos, principalmente devido ao contato com africanos e o crescimento do culto a Ifá. 
Questiono-me se essa construção fotográfica não teria forte influência de Verger, visto que se sabe que ele fazia a ponte cultural e litúrgica entre África e Bahia no vai-e-vem de suas pesquisas.

Outro dado que corroboraria para essa "montagem" realizada por Verger é o fato de que, como é sabido até mesmo pela tradição oral, a iaô fotografada, Sofia de Mavambo, não era da tradição ketu, tendo sido iniciada pelo Tata Ciríaco do Tumba Junsara, casa tradicional da nação angola.

Podemos observar, nas três fotos de Sofia disponíveis na Fundação Pierre Verger, que o orixá não está dentro de uma roda de candomblé, como todas as outras fotos do transe sagrado de outros orixás - está paramentado sozinho, do lado de fora da casa. Questiono-me se essa construção fotográfica não teria forte influência de Verger, visto que ele fazia a ponte cultural e litúrgica entre Áfricas e Bahia no vai e vem de suas pesquisas.

O que posso afirmar é que havia, sem sombra de dúvidas, um grande intercâmbio entre intelectuais e artistas da época. É notável que há, por exemplo, uma grande semelhança entre o Exu fotografado por Verger e o idealizado nos desenhos de Carybé: a mesma roupa, os mesmos instrumentos, paramentos e a mesma postura corporal, mostrando que essa construção imagética atravessa os meios acadêmicos, artísticos e culturais. Na prancha esculpida em madeira que se encontra no Museu Afro da Universidade Federal da Bahia, localizado na histórica Escola de Medicina, que fica no Pelourinho, nota-se que Carybé continua idealizando, como Verger, um Exu nos moldes da tradição africana, não esquecendo, porém, mesmo que discretamente, de expor um tridente.

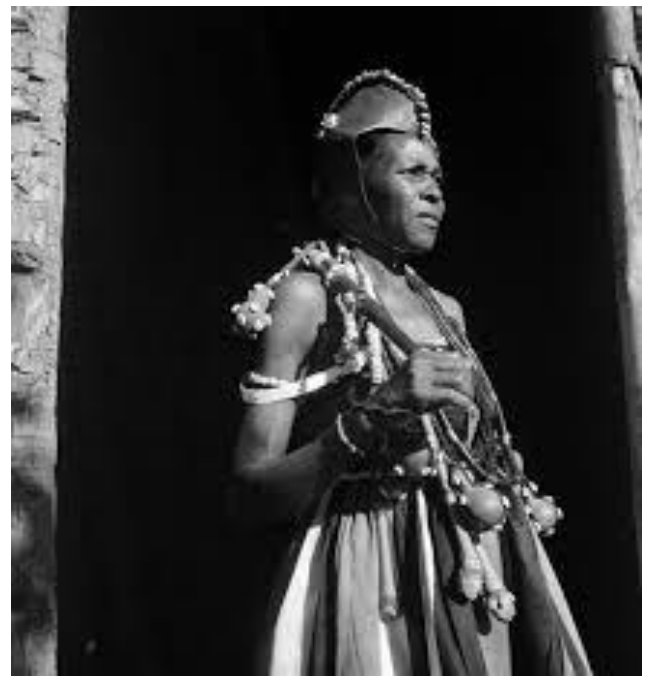

Figura 1.Exu de Verger

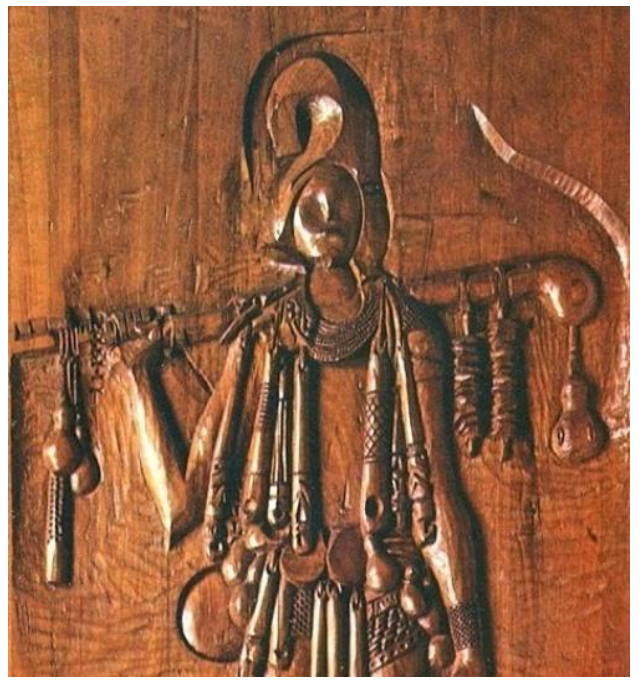

Figura 2: Exu de Carybé 
A roupa, os instrumentos, as paramentas e a postura corporal são os mesmos, demonstrando que tanto o meio acadêmico quanto o meio cultural comungavam das mesmas construções. Em sua Prancha esculpida em madeira, que se encontra no Museu Afro da Bahia, Carybé continua idealizando como Verger um Exu africano, não esquecendo, porém, mesmo que discretamente, de expor um tridente.

A busca pela legitimidade de uma matriz africana, idealizada por pesquisadores das religões afro-brasileiras, influenciou a liturgia das comunidades de culto no Brasil, transformando a relação existente entre as diversas casas. As obras de autores como Pierre Verger (1999) e Juana Elbein dos Santos (2012) foram um marco neste sentido, sendo seguidas por diversos outros autores contemporâneos, estudiosos e religiosos. A internet e a interação através dos diversos meios de comunicação facilitaram e encorajaram posturas de alcance mais amplo e global.

\footnotetext{
As redes sociais constituem um grande aliado ao povo do candomblé. É uso comum nos candomblecistas a internet como ponto de pesquisa e comunicação entre Sacerdotes e iniciados. A proliferação de grupos nas redes sociais e a inclusão doa adeptos do Candomblé em diversos grupos, ao mesmo tempo, cria uma rede ampla de informações que circulam muito rapidamente. (OLIVEIRA JUNIOR, 2018, p.14)
}

O culto a Exu, como orixá africano, é uma realidade, sendo, hoje, a resistência à sua iniciação uma prática de pouquíssimas casas, que carregam a alcunha de tradicionais e procuram se manter fiéis às suas ideologias iniciais. A foto de Verger, assim como a arte de Carybé, cristalizou uma forma característica de ser desse orixá que foi replicada por algumas casas de santo, sem maiores problematizações. Entretanto, enquanto um babalorixá e pesquisador que sou, sinto na pele uma parte da natureza dinâmica e inexplicável desta divindade. Também tenho feito da parte explicável, uma bandeira de luta tanto para o entendimento deste Orixá na sociedade, quanto com a finalidade de colocar na gira epistemológica saberes e fazeres oriundos destas matizes. Para tanto, o trabalho de reflexão e descolonização de sua imagética, bem como de elaboração de novas imagens, desponta como possibilidade da construção de novas narrativas a partir de olhares negros. 


\section{Referências}

ABRAHAM, R.C. Dictionary of Modern Yoruba. London: University of London Press. 1958.

BOUCHE, P-B. Sept Ans en Afrique Occidentale: la Côte des Esclaves et le Dahomey. Paris: Plon, Nourrit \& Cie. 1885.

CALDEIRA, Sofia. As potencialidades do estudo da imagem fotográfica na antropologia visual. In Vista - Revista de Cultura Visual, № 1 - Políticas do olhar. Lisboa: Sociedade Portuguesa de Ciências da Comunicação, 2017.

CAPONE, Stefania. A Busca da África no Candomblé: tradição e poder no Brasil. Rio de Janeiro: Contra Capa Livraria/Pallas, 2009.

CROWTER, Samuel. A vocabulary of Yoruba Language. London: Seeleys. 1852.

MAUPOIL, Bernard. La géomanci à l'anciene Côte des Esclaves. Paris: Institut d'Ethnologie, 1988.

MELO, Aislan Vieira de. Reafricanização e Dessincretização do Candomblé: movimentos de um mesmo processo. Revista Anthropológicas, ano 12, v. 19(2): 157$182,2008$.

OLIVEIRA JUNIOR, Geraldo Barboza de. A religiosidade afro-brasileira na história do Rio Grande do Norte no início do século XXI: intolerância contínua versus resistência crescente. Revista Trabalhos de Antropologia e Etnologia, v. 58, 2018.

SANTOS, Juana Elbein dos. Os Nagô e a Morte: pade, àsèsè e o culto Égun na Bahia. $14^{\mathrm{a}}$ ed. - Petrópolis: Vozes, 2012.

VALLADO, Armando. Os Percalços da Africanização. Trabalho apresentado no Congresso de Umbanda e Candomblé. Diadema, São Paulo, 1999.

VEIGA, Rychelmy Imbiriba. Um menino na Bahia em busca de Pai Procópio de Ogunjá. Salvador: Vento Leste, 2018.

VERGER, Pierre Fatumbi. Notas sobre o Culto aos Orixás e Voduns na Bahia de Todos os Santos, no Brasil, e na Antiga Costa dos Escravos, na África. Tradução: Carlos Eugênio Marcondes de Moura. São Paulo: Editora da Universidade de São Paulo, 1999.

Corrupio, 1981.

Orixás: deuses iorubas da África e do Novo Mundo. Salvador:

Recebido em: 16/12/2020

Aceito em: 16/12/2020 